\title{
The effect of OSAS on sick leave and work disability
}

\author{
B. Sivertsen*, S. Øverland ${ }^{\#}$, N. Glozier", B. Bjorvatn ${ }^{+, \S}$, \\ J.G. Mæland ${ }^{+}$and A. Mykletun ${ }^{\#, f}$
}

ABSTRACT: The objective of the present study was to examine the independent contribution of symptoms of obstructive sleep apnoea syndrome (OSAS) to long-term sick leave and permanent work disability.

Using a historical cohort design with 4 yrs of follow-up, information on sick leave and disability benefit recipiency were merged with health information from the Hordaland Health Study, carried out in western Norway during 1997-1999. Persons aged 40-45 yrs $(n=7,028)$ were assessed for self-reported symptoms of OSAS (snoring, breathing cessations and daytime sleepiness), body mass index, somatic conditions and other potential confounders. The outcomes, cumulative sick leave of $\geqslant 8$ weeks and permanent work disability, were identified in records from the National Insurance Administration.

After excluding participants with work disability at baseline, symptoms of OSAS were found to be a significant predictor of both subsequent long-term sick leave and permanent work disability. These effects remained significant after adjustment for a range of possible confounding factors. Daytime sleepiness showed the greatest explanatory power, followed by breathing cessations and snoring.

It is concluded that self-reported symptoms of obstructive sleep apnoea syndrome are an independent risk factor for subsequent long-term sick leave and permanent work disability. These findings need to be replicated using objective measures of obstructive sleep apnoea syndrome.

KEYWORDS: Epidemiology, obstructive, population-based, risk factors, sickness absence, sleep apnoea

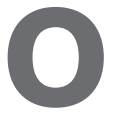

bstructive sleep apnoea syndrome (OSAS) is a sleep disorder in which the upper airway closes repeatedly during sleep, leading to sleep fragmentation and decreased levels of oxyhaemoglobin saturation [1]. The prevalence of OSAS is estimated to be $\sim 5 \%$ [2-8], but the at-risk population is likely to be much larger [9]; only $10 \%$ of the population are adequately screened for this diagnosis [10]. Clinically characterised by snoring, breathing cessations and extreme daytime somnolence [11], OSAS has been shown to be a risk factor for a range of medical conditions, including glucose intolerance [12], impotence [13], hypertension [14], myocardial infarction [15], and stroke and mortality [16]. Untreated OSAS also increases the risk of automobile accidents [17], leads to poor quality of life [18] and has been linked with several neurocognitive consequences $[19,20]$.

In addition to such impacts on individual health, an Australian study recently estimated the economic costs of sleep disorders (OSAS and insomnia being the most important) to represent almost $1 \%$ of Australia's gross domestic product [21]. In addition, despite previous studies consistently showing self-reported sleep problems in general to be a significant risk factor for both long-term sick leave and permanent work disability determined objectively [22-24], the only recent study investigating OSAS severity and self-reported work limitation yielded mixed results [25]. To the best of the present authors' knowledge, no studies to date have prospectively aimed to study the independent effects of symptoms of OSAS on long-term sick leave or permanent work disability.

Although polysomnography (PSG) is recommended for making the diagnosis of OSAS, it is not easily applied in large population-based studies, being intrusive, impractical and expensive. Therefore, screening instruments based on self-reported symptoms of OSAS have been necessary in order to gain information on both
AFFILIATIONS

Depts of ${ }^{*}$ Clinical Psychology,

"Education and Health Promotion, and

+Public Health and Primary Health Care, University of Bergen, and ${ }^{\S}$ Norwegian Competence Center for Sleep Disorders, Haukeland University Hospital, Bergen, and ${ }^{f}$ Dept of Mental Health, Division of Epidemiology, Norwegian Institute of Public Health, Oslo, Norway. "Neurological/Mental Health Division, The George Institute for International Health and University of Sydney, Sydney, Australia

CORRESPONDENCE

B. Sivertsen

Dept of Clinical Psychology University of Bergen

Christiesgt. 12 5015 Bergen Norway

Fax: 4755589877

E-mail: borge.sivertsen@

psykp.uib.no

Received:

March 242008

Accepted after revision:

July 092008

STATEMENT OF INTEREST

None declared.

European Respiratory Journal Print ISSN 0903-1936 Online ISSN 1399-3003 
the prevalence and comorbid conditions of OSAS [3, 4, 9], information that would be hard to obtain without using largescale surveys.

The aim of the present study was to estimate the effect of selfreported symptoms of OSAS on both long-term sick leave and permanent work disability, using a historical cohort design. Importantly, the aim was also to adjust for the effect of a range of possible confounding and mediating factors known to be associated with OSAS, including demographic factors, lifestyle behaviours, marital/cohabitant status, body mass index and blood pressure, as well as other physical diagnoses and conditions.

\section{METHODS}

\section{Population and data material}

The Hordaland Health Study (HUSK) was a joint epidemiological research project carried out during 1997-1999 by the Norwegian Health Screening Service (Oslo, Norway) in collaboration with the University of Bergen (Bergen, Norway). The base population included 29,400 individuals in the county of Hordaland (western Norway) born during 19531957 and aged $40-45$ yrs at the time of data collection. Data were collected by questionnaire and clinical examination. A total of 18,581 subjects (8,598 males and 9,983 females) both answered the basic questionnaire and attended for clinical examination, yielding a participation rate of $63 \%$ (57\% for males and $70 \%$ for females).

After the clinical examination, a second questionnaire, including the OSAS items, was distributed and completed by a random subgroup comprising 8,896 individuals. Owing to nonresponse to one or more of the variables relevant to the present study in the second set of questions, 1,600 individuals were excluded. HUSK responders who were receiving disability pension at baseline or who were granted disability pension awards within 12 months following baseline were also excluded $(n=268)$, as were also individuals on sick leave at the time of the HUSK and 14 days thereafter. Thus, the final population consisted of 7,028 individuals.

\section{Measures}

\section{Outcome}

The Norwegian National Insurance Administration (Oslo, Norway) records all periods of sick leave of $>14$ days, as well as all disability pension awards. In Norway, this is in all respects a public responsibility, and, since correct registration is a prerequisite for transfers of payments, the records are highly accurate.

In the present study, long-term sick leave was defined as cumulative sick leave of $\geqslant 8$ weeks (56 days). A cut-off of 8 weeks has also been used in similar studies to denote long term $[23,26]$.

Permanent work disability was defined as award of a disability pension 12-48 months after participation in the HUSK. By excluding all disability pensions awarded from baseline to 12 months after participation in the HUSK, the aim was to exclude subjects in the process of applying for a disability pension while they attended the HUSK, thus reducing any possible protopathic bias. In the present study, the term work disability is synonymous with disability pension award.
The criterion for being awarded a disability pension is a $\geqslant 50 \%$ permanently reduced work ability due to an acknowledged medical condition as certified by a general practitioner. Examinations by a specialist are undertaken when appropriate, although such independent examination is not required.

\section{Exposure}

Symptoms of OSAS were estimated using three items from the Karolinska Sleep Questionnaire [27]. These self-report items were used to identify at-risk individuals based on their own or their partner's reports on snoring and breathing cessation during sleep. In addition to the requirement for reporting both of these core symptoms as occurring either "sometimes (several times a month)", "often (several times a week)" or "always", participants were only classified as having symptoms of OSAS if they were also "tired or sleepy at work or during their spare time" "sometimes", "often" or "always". A similar definition based on the Hawaii Sleep Questionnaire (the apnoea score) has previously been shown to identify $100 \%$ of cases with moderate or severe sleep apnoea (apnoea/ hypopnoea index (AHI) of $>40$ ) and $75 \%$ of all sleep apnoea cases with an AHI of $>5$, yielding an overall predictive accuracy of $88 \%$ for an AHI of $>10$ [28].

\section{Potential confounders}

Alcohol consumption was operationalised using four categories based on self-reported weekly consumption $(0,1-2,3-4$ and $\geqslant 5$ units. week $\left.^{-1}\right)$. Body mass index was calculated from body weight (in kilograms) divided by height (in metres) squared obtained from clinical examination. Level of education was reported in four categories ranging from $<7 \mathrm{yrs}$ of schooling to $\geqslant 4$ yrs of higher education at college/university. Type of main occupation was manually classified according to the European Union variant of the International Standard Classification of Occupations (ISCO-88 (COM)) [29] and divided into the 10 major groups (e.g. professionals). A detailed description of these categories is provided elsewhere [30]. Data were also collected on marital/cohabitant status (dichotomised into living alone or with partner), smoking status (current smoker or not) and weekly level of exercise (1: no or easy physical activity for $1 \mathrm{~h} \cdot$ week $^{-1} ; 2$ : moderate physical activity for $1-2 \mathrm{~h} \cdot$ week $^{-1}$; or 3 : hard physical activity for $>2 \mathrm{~h} \cdot$ week $^{-1}$ ). Data on blood pressure were collected during the clinical examinations.

Symptoms of current depression were measured using the depression subscale of the hospital anxiety and depression scale [31], which is a self-report questionnaire comprising 14 four-point Likert-scaled items, seven of which are used to construct the depression subscale. No somatic items or items regarding sleeping difficulties are included. The scale was used as a continuous variable, reflecting symptom load of depression.

Questions on somatic diagnoses were framed in the form: "do you have or have you had (one or more of the following)" myocardial infarction, stroke, diabetes and angina. A positive response to one or more of these items was considered a positive self-reported diagnosis. In addition, participants were asked whether or not they had used any medication on the previous day, and, if so, for which condition. From these responses, a team of physicians determined appropriate 
diagnoses according to anatomical therapeutic chemical classifications, producing a continuous variable indicating the number of conditions for which the person was taking medication.

In the present article, no discrimination was made between confounding and mediating factors.

\section{Statistical analysis and models}

Pearson's Chi-squared tests were used to examine differences in baseline demographic and clinical characteristics in persons with and without symptoms of OSAS. Multivariate logistic regression analysis was used to examine the relation between symptoms of OSAS and sick leave and award of a disability pension. In order to avoid double counting, participants who were granted disability pension awards during the follow-up $(n=139)$ were excluded from the sick leave analyses. However, because of the high prevalence of sick leave, participants on sick leave $(n=1,790)$ were not excluded when work disability was the outcome measure. Data are presented as odds ratios (ORs) with 95\% confidence intervals (CIs). The following potential confounders (determined a priori) were entered into the model for adjustment in: 1) demographic characteristics (age and education), 2) marital/cohabitant status, 3) health behaviours (smoking, alcohol and physical exercise), 4) body mass index, 5) systolic blood pressure, 6) somatic diagnoses (angina, stroke, diabetes and myocardial infarction), and 7) prescribed drugs.

\section{Ethics}

The study protocol was cleared by the Regional Committee for Medical Research Ethics of Western Norway and approved by the Norwegian Data Inspectorate (both Bergen, Norway). Informed consent was obtained in writing from all subjects included in the present study.

\section{RESULTS}

\section{Sample characteristics}

The baseline characteristics of the 7,028 participants that completed the OSAS questionnaire are shown in table 1. The prevalence rate of OSAS was found to be $6.3 \%$. Symptoms of OSAS were more prevalent among males and persons with low educational level. Being a current smoker, less exercise, higher alcohol consumption and high body mass index were all associated with reported symptoms of OSAS. Higher systolic blood pressure was also associated with reported symptoms of OSAS, whereas angina, stroke, diabetes and myocardial infarction were not (table 1).

\section{The effect of symptoms of obstructive sleep apnoea syndrome on sick leave}

Persons reporting symptoms of OSAS showed an almost doubled OR for subsequent sick leave during follow-up adjusting for sex alone (OR 1.78 (95\% CI 1.42-2.20); table 2). Adjusting for age and education reduced the OR to 1.70, whereas controlling for either body mass index or depression reduced the OR to 1.71. Health behaviours, including smoking, alcohol and physical exercise, had a slightly larger explanatory effect on the relationship between OSAS and sick leave, with an adjusted OR of 1.67 (95\% CI 1.33-2.08). However, even in

\begin{tabular}{|c|c|c|c|c|}
\hline \multirow{3}{*}{\multicolumn{2}{|c|}{$\begin{array}{cl}\text { TABLE } 1 & \text { Baselin } \\
& \text { charact } \\
& \text { self-rep } \\
\text { syndron } \\
\text { Hordala }\end{array}$}} & \multicolumn{3}{|c|}{$\begin{array}{l}\text { Baseline demographic and clinical } \\
\text { characteristics of participants with and without } \\
\text { self-reported obstructive sleep apnoea } \\
\text { syndrome (OSAS) symptoms in the Norwegian } \\
\text { Hordaland Health Study }\end{array}$} \\
\hline & & \multicolumn{2}{|c|}{ OSAS symptoms } & \multirow[t]{2}{*}{$\mathrm{p}$-value } \\
\hline & & Absent & Present & \\
\hline \multicolumn{2}{|l|}{ Subjects } & $6588(93.7)$ & $440(6.3)$ & \\
\hline \multicolumn{2}{|l|}{ Sex } & & & $<0.001$ \\
\hline \multicolumn{2}{|l|}{ Male } & 36.6 & 65.2 & \\
\hline \multicolumn{2}{|l|}{ Female } & 63.4 & 34.8 & \\
\hline \multicolumn{2}{|c|}{ Living with partner } & 76.5 & 73.6 & 0.18 \\
\hline \multicolumn{2}{|c|}{ Education } & & & 0.002 \\
\hline \multicolumn{2}{|l|}{ Primary } & 16.7 & 20.7 & \\
\hline \multicolumn{2}{|c|}{ Secondary } & 45.0 & 49.3 & \\
\hline \multicolumn{2}{|c|}{ 1-3 yrs higher } & 19.8 & 17.5 & \\
\hline \multicolumn{2}{|c|}{$\geqslant 4$ yrs higher } & 18.4 & 12.5 & \\
\hline \multicolumn{2}{|c|}{ Occupational type ${ }^{\#}$} & & & $<0.001$ \\
\hline \multicolumn{2}{|c|}{$\begin{array}{l}\text { Legislators/senior } \\
\text { officials/managers }\end{array}$} & 15.1 & 18.0 & \\
\hline \multicolumn{2}{|c|}{ Professionals } & 9.1 & 7.3 & \\
\hline \multicolumn{2}{|c|}{$\begin{array}{l}\text { Technicians/associate } \\
\text { professionals }\end{array}$} & 22.1 & 19.0 & \\
\hline \multicolumn{2}{|c|}{ Clerks } & 13.8 & 14.6 & \\
\hline \multicolumn{2}{|c|}{$\begin{array}{l}\text { Shop/market sales and } \\
\text { service workers }\end{array}$} & 20.4 & 13.9 & \\
\hline \multicolumn{2}{|c|}{$\begin{array}{l}\text { Agricultural/forestry/ } \\
\text { fishery workers }\end{array}$} & 2.0 & 1.0 & \\
\hline \multicolumn{2}{|c|}{$\begin{array}{l}\text { Craft and related } \\
\text { trades workers }\end{array}$} & 7.3 & 13.4 & \\
\hline \multicolumn{2}{|c|}{$\begin{array}{l}\text { Plant/machine operators/ } \\
\text { assemblers }\end{array}$} & 4.7 & 7.1 & \\
\hline \multicolumn{2}{|c|}{ Elementary occupations } & 5.0 & 4.4 & \\
\hline Armed forc & & 0.4 & 1.2 & \\
\hline Current smo & & 32.6 & 48.0 & $<0.001$ \\
\hline Alcohol con & mption & & & $<0.001$ \\
\hline 0 units.wee & & 29.0 & 22.7 & \\
\hline $1-2$ units. $w$ & & 41.8 & 37.3 & \\
\hline $3-4$ units $\cdot w$ & & 14.6 & 12.5 & \\
\hline$\geqslant 5$ units $\cdot w$ & & 14.6 & 27.5 & \\
\hline Physical exe & & & & 0.14 \\
\hline No or easy & & 29.3 & 33.4 & \\
\hline Moderate & & 57.0 & 55.0 & \\
\hline Heavy & & 13.7 & 11.6 & \\
\hline Body mass $i$ & & & & $<0.001$ \\
\hline$<25$ & & 55.0 & 36.8 & \\
\hline $25-30$ & & 35.8 & 41.6 & \\
\hline$>30$ & & 9.2 & 21.6 & \\
\hline Angina & & 0.3 & 0.2 & 1.00 \\
\hline Stroke & & 0.3 & 0.2 & 1.00 \\
\hline Diabetes & & 0.7 & 0.9 & 0.56 \\
\hline Myocardial i & arction & 0.2 & 0.5 & 0.17 \\
\hline Depression & & $2.97(2.90-3.04)$ & $4.26(3.97-4.55)$ & $<0.001$ \\
\hline $\begin{array}{c}\text { Blood press } \\
\text { (systolic) }\end{array}$ & & $125.9(125.6-126.3)$ & $129.8(128.5-131.1)$ & $<0.001$ \\
\hline Prescribed c & & $0.08(0.07-0.09)$ & $0.07(0.04-0.09)$ & 0.87 \\
\hline
\end{tabular}

Data are presented as $n(\%), \%$ or mean (95\% confidence interval), unless otherwise indicated. \#: listed in descending order from white- to blue-collar occupations (see [30]). 1 unit alcohol $\approx 12 \mathrm{~g}$ ethanol. 


\begin{tabular}{ll}
\hline TABLE 2 & $\begin{array}{l}\text { Multivariate logistic regression analyses of the } \\
\text { effect of self-reported symptoms of obstructive } \\
\text { sleep apnoea syndrome (OSAS) on long-term }\end{array}$ \\
sick leave in the Norwegian Hordaland Health \\
Study
\end{tabular}

Of the at-risk population of 6,919 subjects, 1,824 had had $\geqslant 8$ weeks of sick leave. OR: odds ratio; $\mathrm{Cl}$ : confidence interval. ${ }^{\#}$ : $\geqslant 8$ weeks; ": adjusting for all of the above confounders.

the fully adjusted model, symptoms of OSAS remained a significant risk factor for long-term sick leave (adjusted OR 1.62 (95\% CI 1.28-2.05)).

\section{The effect of symptoms of obstructive sleep apnoea syndrome on disability pension award}

Persons reporting symptoms of OSAS showed a more than doubled OR for subsequent award of a disability pension during follow-up, and adjusting for sex, age and education only slightly attenuated the association (adjusted OR 2.20 (95\% CI 1.26-3.85); table 3). Health behaviours also explained some of this association (adjusted OR 1.99), as did depression (adjusted OR 2.02). As was the case for sick leave, neither occupational type, marital status, prescribed drugs, blood pressure, angina, stroke, diabetes nor myocardial infarction had a significant explanatory effect on the relationship between OSAS and work disability. When adjusting for the entire list of confounders, symptoms of OSAS remained a significant risk factor for permanent work disability (OR 1.92 (95\% CI: 1.01-3.66)).

\section{The separate effects of breathing cessations, snoring and daytime sleepiness}

In order to examine which of the components (breathing cessations, snoring or daytime sleepiness) had the greatest explanatory power on sick leave and permanent work disability, additional analyses were conducted on each of the three components included in the OSAS variable. As detailed in table 4, daytime sleepiness was a stronger risk factor than snoring and breathing cessations for both sick leave (adjusted OR 1.36) and work disability (adjusted OR 2.03). Snoring was only significantly associated with subsequent sick leave in the crude analyses (OR 1.15 (95\% CI 1.10-1.21)), whereas breathing
TABLE 3 Multivariate logistic regression analyses of the effect of self-reported symptoms of obstructive sleep apnoea syndrome (OSAS) on permanent work disability in the Norwegian Hordaland Health Study

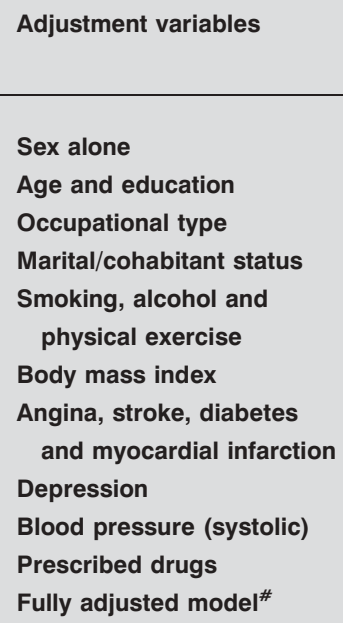

Of the at-risk population of 7,028 subjects, 139 had a subsequent disability pension award. OR: odds ratio; $\mathrm{Cl}$ : confidence interval. ${ }^{*}$ : adjusting for all of the above confounders.

cessations also remained a significant risk factor in the fully adjusted analyses for sick leave (adjusted OR 1.08 (95\% CI 1.01-1.66)), but not for work disability.

As detailed in figure 1, there was a dose-response relationship between the frequency of symptoms and long-term sick leave. Experiencing each of the symptoms always yielded higher ORs compared to often or sometimes. This effect was more evident in terms of daytime sleepiness, followed by breathing cessations and snoring. A similar dose-response relationship was also found when the outcome was permanent work disability.

\section{DISCUSSION}

In the present study, it was found that self-reported symptoms of OSAS (snoring, breathing cessations and daytime sleepiness) were a strong risk factor for both subsequent long-term sick leave and award of disability pensions. Daytime sleepiness had the strongest explanatory effect, but breathing cessations and snoring also contributed to the effect of OSAS on these adverse outcomes. As expected, a range of adverse sociodemographic characteristics and health behaviours and states were associated with OSAS, which partly explained this association. However, even controlling for all of these factors, OSAS remained a strong risk factor for these poor outcomes.

These findings add to the understanding of OSAS as a sleep disorder with serious consequences, both individual and social. In addition to being a risk factor for a range of medical conditions [12-16], OSAS has also been demonstrated to cause variable degrees of cognitive and performance problems. Although the causal mechanisms leading to such deficits remain unclear, postulated mediating conditions (e.g. hypertension, angina, myocardial infarction, diabetes and stroke) of 


\begin{tabular}{|c|c|c|c|c|}
\hline TABLE 4 & $\begin{array}{l}\text { gression analyses } \\
\# \text { sick leave and }\end{array}$ & $\begin{array}{l}\text { effect of items com } \\
\text { ent work disability in }\end{array}$ & $\begin{array}{l}\text { the obstructiv } \\
\text { rwegian Hord }\end{array}$ & $\begin{array}{l}\text { apnoea syndrome } \\
\text { ealth Study }\end{array}$ \\
\hline Outcome/model & Composite variable & Breathing cessations & Snoring & Daytime sleepiness \\
\hline \multicolumn{5}{|c|}{ Long-term sick leave } \\
\hline Crude & $1.78(1.42-2.20)$ & $1.23(1.15-1.32)$ & $1.15(1.10-1.21)$ & $1.37(1.28-1.47)$ \\
\hline Fully adjusted & $1.62(1.28-2.05)$ & $1.08(1.01-1.16)$ & $1.03(0.98-1.08)$ & $1.36(1.27-1.46)$ \\
\hline Crude & $2.40(1.38-4.19)$ & $1.32(1.10-1.60)$ & $1.08(0.94-1.25)$ & $2.26(1.85-2.76)$ \\
\hline Fully adjusted & $1.92(1.01-3.66)$ & $1.09(0.88-1.35)$ & $0.93(0.79-1.10)$ & $2.03(1.61-2.57)$ \\
\hline
\end{tabular}

the effect of OSAS had no explanatory power in the present models, suggesting that the symptoms of OSAS do not lead to these negative outcomes through these mechanisms. OSAS patients have been shown to report problems in cognitive processing, memory, sustained attention and executive functioning [32]. As such, untreated OSAS represents a major problem for the patient $24 \mathrm{~h}$ per day, with impaired daytime functioning, expressed as forgetfulness, impaired concentration, and slowed thought processes and responses. It comes as no surprise, then, that having symptoms of OSAS is associated with subjective reported problems in work performance [33]. Although sleep complaints in general have been found to predict later work disability [24], to the present authors' knowledge, only three other studies have examined the relation between OSAS and work performance. In a retrospective Swedish study, self-reported symptoms of OSAS were found to be significantly associated with short-term sick leave and psychosocial morbidity in a sample of obese persons [34]. In this study, persons with OSAS reported, on average, 5 weeks more sick leave over the previous year than those without OSAS, an effect that remained significant after

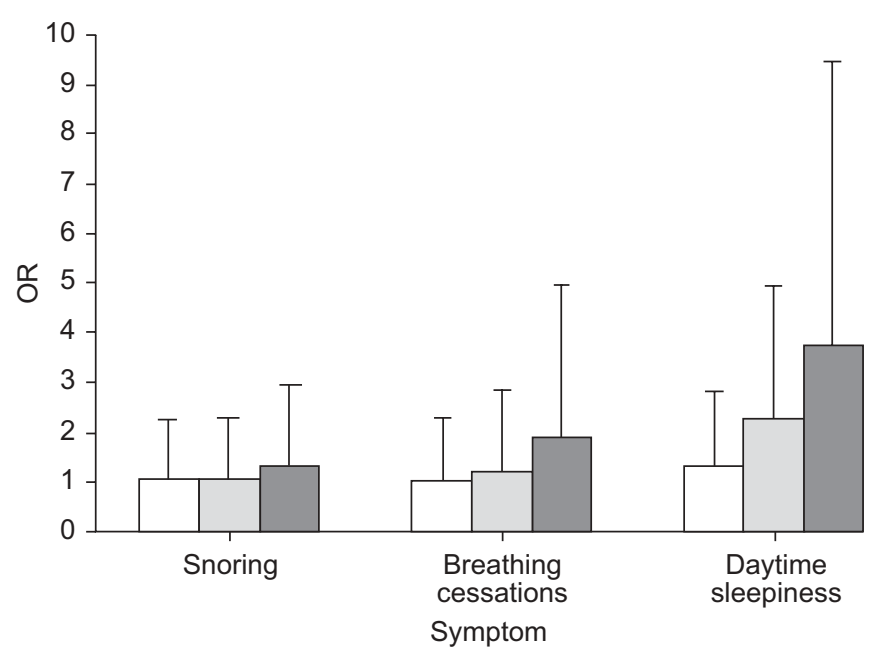

FIGURE 1. Multivariate logistic regression analyses of effect of frequencies (sometimes: $\square$; often: $\square$; always: $\square$ ) of symptoms comprising the obstructive sleep apnoea syndrome variable (compared to symptoms reported rarely or never) on long-term sick leave in the Norwegian Hordaland Health Study. Vertical bars represent 95\% confidence intervals. OR: odds ratio. adjusting for the presence of other common disorders, such as hypertension and diabetes. In another recent study, MULGREW et al. [25] found no relationship between OSAS severity and self-reported work limitation in white-collar workers, whereas such an association was present in bluecollar workers. However, these studies did not attempt to adjust for potential confounders that might explain their findings. Finally, LINDBERG et al. [35] found self-reported snoring and daytime sleepiness to double the risk of occupational accidents during a 10-yr follow-up period, an effect that remained significant when adjusting for other factors that might explain their findings, including body mass index smoking, alcohol dependence and working lifetime, as well as various occupational factors.

The present findings show that, among the three symptoms constituting the OSAS variable, daytime sleepiness was the strongest risk factor for both sick leave and work disability, followed by breathing cessations and snoring. In addition, not surprisingly, a dose-response relationship was found between the frequency of symptoms and outcomes, with those always experiencing daytime sleepiness having the worst workrelated outcome. However, it is worth noting that the combination of these symptoms generally yielded higher ORs than any of the individual symptoms alone (except in the fully adjusted analyses on work disability, in which the OR for sleepiness was comparable to that for the OSAS variable).

There are several strengths of the present study. First, the study sample was relatively large and the participation rate was high. Secondly, both exposure and outcome assessments should be relatively unbiased. At baseline measurement, neither participants nor administrators were aware of the specific research hypotheses, reducing the possibility of information being biased by selective symptom presentation in order to gain access to, or avoid, benefits or bias the results in the direction of a particular hypothesis. Thirdly, the data obtained from the National Insurance Administration are complete, since people moving to other parts of Norway after participation in the HUSK remained registered. The main limitation of the present study is the measurement of OSAS. Rather than employing the gold standard of a clinical diagnosis based on PSG recordings, the present study is based on a brief self-report questionnaire used to categorise persons into two groups, those with and without symptoms of OSAS. The prevalence estimate $(6.3 \%)$ was similar to that found in 
other epidemiological studies based on the general population in cohorts of a similar age [2-5, 7]. Nevertheless, the use of selfreported symptoms to measure OSAS remains potentially problematic, since persons are often unaware of their behaviour during sleep [36]. However, PSG data are not easily obtained in epidemiological studies, and the use of self-reports by patients are often the only feasible means of acquiring information about sleep behaviour. One way of improving the validity of such reports is by also including spouse-reported information on snoring and breathing cessations [36]. The Karolinska Sleep Questionnaire is also based on sleep problems reported by the person's spouse and thus attempts to improve the validity of symptoms. However, as noted by GRUNSTEIN et al. [34], a potential source of misclassification into OSAS and non-OSAS groups may relate to the presence of a current home partner, and persons sleeping alone may, as such, be more likely to be misclassified as not having OSAS. In the present analysis, adjusting for marital/cohabitant status did not attenuate the effect, and such a misclassification would tend to produce an underestimation of the health differences between the OSAS and non-OSAS groups, given that living alone is characteristically associated with poorer health [34].

In addition, previous studies have shown that self-report exhibits an acceptable level of accuracy in identifying subjects with and without OSAS [28, 37-40]. In an early study by KAPUNIAI et al. [28], the same operationalisation of OSAS predicted an apnoea index of $>10$ with a sensitivity of $83 \%$ and specificity of $63 \%$. Another study found this operationalisation to yield a very high level of specificity for OSAS (99\%), although the sensitivity was somewhat lower [37]. In that study, it was also found that persons never reporting snoring and having no observed apnoea were 35 times less likely to have OSAS (as indicated by PSG) compared to those with positive responses to these questions. Nevertheless, under ideal circumstances, self-report data should be validated by PSG readings, although this is rarely performed in such large population studies [41]. A suggestion for further studies including items on sleep apnoea might be to run PSG on a subsample in order to validate the self-reports.

The rate of receipt and later award of disability pension was higher among nonparticipants than among participants of the HUSK study [42]. Nonparticipants also have poorer health [43] and much higher mortality rates [44]. Thus the present results might be more accurate for a relatively healthier subset of the population. Among nonrespondents, there were possibly more comorbid conditions and complex health problems leading to work disability.

Finally, there are other potential confounders, such as work pressures, stress and other medical conditions (including glucose intolerance, impotence and neurocognitive deficits), that have not been captured in the present measures but which may yet be related to both baseline symptoms of OSAS and later sick leave or disability pension.

\section{Conclusions}

The present findings suggest that persons with self-reported symptoms of obstructive sleep apnoea syndrome are more likely to leave the work force, and that this sleep disorder may be a significant independent contributor to increased social security costs and reduced productivity and family income.
The findings warrant replication using a better-validated measure of obstructive sleep apnoea syndrome, and suggest that social outcomes should become an additional focus of interventions.

\section{REFERENCES}

1 Guilleminault C, Bassiri A. Clinical features and evaluation of obstructive sleep apnea. In: Kryger M, Roth T, Dement W, eds. Principles and Practice of Sleep Medicine. 4th Edn. Philadelphia, W.B. Saunders, 2005; pp. 1043-1052.

2 Bresnitz EA, Goldberg R, Kosinski RM. Epidemiology of obstructive sleep apnea. Epidemiol Rev 1994; 16: 210-227.

3 Kripke DF, Ancoli-Israel S, Klauber MR, Wingard DL, Mason WJ, Mullaney DJ. Prevalence of sleep-disordered breathing in ages 40-64 years: a population-based survey. Sleep 1997; 20: 65-76.

4 Ohayon MM, Guilleminault C, Priest RG, Caulet M. Snoring and breathing pauses during sleep: telephone interview survey of a United Kingdom population sample. BMJ 1997; 314: 860-863.

5 Partinen M. Epidemiology of obstructive sleep apnea syndrome. Curr Opin Pulm Med 1995; 1: 482-487.

6 Tishler PV, Larkin EK, Schluchter MD, Redline S. Incidence of sleep-disordered breathing in an urban adult population: the relative importance of risk factors in the development of sleep-disordered breathing. JAMA 2003; 289: 2230-2237.

7 Young T, Palta M, Dempsey J, Skatrud J, Weber S, Badr S. The occurrence of sleep-disordered breathing among middle-aged adults. N Engl J Med 1993; 328: 1230-1235.

8 Young T, Peppard PE, Gottlieb DJ. Epidemiology of obstructive sleep apnea: a population health perspective. Am J Respir Crit Care Med 2002; 165: 1217-1239.

9 Hiestand DM, Britz P, Goldman M, Phillips B. Prevalence of symptoms and risk of sleep apnea in the US population: results from the National Sleep Foundation Sleep in America 2005 poll. Chest 2006; 130: 780-786.

10 Young T, Evans L, Finn L, Palta M. Estimation of the clinically diagnosed proportion of sleep apnea syndrome in middle-aged men and women. Sleep 1997; 20: 705-706.

11 American Academy of Sleep Medicine. The International Classification of Sleep Disorders: Diagnostic and Coding Manual. 2nd Edn. Westchester IL, American Academy of Sleep Medicine, 2005.

12 Babu AR, Herdegen J, Fogelfeld L, Shott S, Mazzone T. Type 2 diabetes, glycemic control, and continuous positive airway pressure in obstructive sleep apnea. Arch Intern Med 2005; 165: 447-452.

13 Goncalves MA, Guilleminault C, Ramos E, Palha A, Paiva T. Erectile dysfunction, obstructive sleep apnea syndrome and nasal CPAP treatment. Sleep Med 2005; 6: 333-339.

14 Peppard PE, Young T, Palta M, Skatrud J. Prospective study of the association between sleep-disordered breathing and hypertension. N Engl J Med 2000; 342: 1378-1384.

15 Hung J, Whitford EG, Parsons RW, Hillman DR. Association of sleep apnoea with myocardial infarction in men. Lancet 1990; 336: 261-264.

16 Yaggi HK, Concato J, Kernan WN, Lichtman JH, Brass LM, Mohsenin V. Obstructive sleep apnea as a risk factor for stroke and death. N Engl J Med 2005; 353: 2034-2041. 
17 Young T, Blustein J, Finn L, Palta M. Sleep-disordered breathing and motor vehicle accidents in a populationbased sample of employed adults. Sleep 1997; 20: 608-613.

18 Ballester E, Badia JR, Hernandez L, et al. Evidence of the effectiveness of continuous positive airway pressure in the treatment of sleep apnea/hypopnea syndrome. Am J Respir Crit Care Med 1999; 159: 495-501.

19 Engleman HM, Kingshott RN, Wraith PK, Mackay TW, Deary IJ, Douglas NJ. Randomized placebo-controlled crossover trial of continuous positive airway pressure for mild sleep apnea/hypopnea syndrome. Am J Respir Crit Care Med 1999; 159: 461-467.

20 Aikens JE, Caruana-Montaldo B, Vanable PA, Tadimeti L, Mendelson WB. MMPI correlates of sleep and respiratory disturbance in obstructive sleep apnea. Sleep 1999; 22: 362-369.

21 Hillman DR, Murphy AS, Antic R, Pezzullo L. The economic cost of sleep disorders. Sleep 2006; 29: 299-305.

22 Akerstedt T, Kecklund G, Alfredsson L, Selen J. Predicting long-term sickness absence from sleep and fatigue. J Sleep Res 2007; 16: 341-345.

23 Eriksen W, Natvig B, Bruusgaard D. Sleep problems: a predictor of long-term work disability? A four-year prospective study. Scand J Public Health 2001; 29: 23-31.

24 Sivertsen B, Overland S, Neckelmann D, et al. The longterm effect of insomnia on work disability: the HUNT-2 historical cohort study. Am J Epidemiol 2006; 163: 10181024.

25 Mulgrew AT, Ryan CF, Fleetham JA, et al. The impact of obstructive sleep apnea and daytime sleepiness on work limitation. Sleep Med 2008; 9: 42-53.

26 Haldorsen EM, Grasdal AL, Skouen JS, Risa AE, Kronholm K, Ursin $\mathrm{H}$. Is there a right treatment for a particular patient group? Comparison of ordinary treatment, light multidisciplinary treatment, and extensive multidisciplinary treatment for long-term sick-listed employees with musculoskeletal pain. Pain 2002; 95: 49-63.

27 Kecklund G, Åkerstedt T. The psychometric properties of the Karolinska Sleep Questionnaire. J Sleep Res 1992; 1: 113.

28 Kapuniai LE, Andrew DJ, Crowell DH, Pearce JW. Identifying sleep apnea from self-reports. Sleep 1988; 11: 430-436.

29 Statistics Norway. Standard Classification of Occupations. Oslo, Statistics Norway, 1999.

30 Sanne B, Mykletun A, Dahl AA, Moen BE, Tell GS. Occupational differences in levels of anxiety and depression: the Hordaland Health Study. J Occup Environ Med 2003; 45: 628-638.
31 Zigmond AS, Snaith RP. The hospital anxiety and depression scale. Acta Psychiatr Scand 1983; 67: 361-370.

32 Weaver T, George C. Cognition and performance in patients with obstructive sleep apnea. In: Kryger M, Roth T, Dement W, eds. Principles and Practice of Sleep Medicine. 4th Edn. Philadelphia, W.B. Saunders, 2005; pp. 1023-1040.

33 Ulfberg J, Carter N, Talback M, Edling C. Excessive daytime sleepiness at work and subjective work performance in the general population and among heavy snorers and patients with obstructive sleep apnea. Chest 1996; 110: 659-663.

34 Grunstein RR, Stenlof K, Hedner JA, Sjostrom L. Impact of self-reported sleep-breathing disturbances on psychosocial performance in the Swedish Obese Subjects (SOS) study. Sleep 1995; 18: 635-643.

35 Lindberg E, Carter N, Gislason T, Janson C. Role of snoring and daytime sleepiness in occupational accidents. Am J Respir Crit Care Med 2001; 164: 2031-2035.

36 Wiggins CL, Schmidt-Nowara WW, Coultas DB, Samet JM. Comparison of self- and spouse reports of snoring and other symptoms associated with sleep apnea syndrome. Sleep 1990; 13: 245-252.

37 Bliwise DL, Nekich JC, Dement WC. Relative validity of self-reported snoring as a symptom of sleep apnea in a sleep clinic population. Chest 1991; 99: 600-608.

38 Crocker BD, Olson LG, Saunders NA, et al. Estimation of the probability of disturbed breathing during sleep before a sleep study. Am Rev Respir Dis 1990; 142: 14-18.

39 Young T. Age dependence of sleep disordered breathing. In: Kuna S, Suratt P, Remmers J, eds. Sleep and Respiration in Aging Adults. New York, Elsevier, 1991; pp. 161-170.

40 Young T. Some methodological and practical issues of reported snoring validity. Chest 1991; 99: 531-532.

41 Quan SF, Howard BV, Iber C, et al. The Sleep Heart Health Study: design, rationale, and methods. Sleep 1997; 20: 1077_ 1085.

42 Øverland S, Glozier N, Henderson M, Hotopf M, Mæland J, Mykletun A. Health before, during and after award of disability pension. The HUSK study. Occup Environ Med 2008; (In press).

43 Holmen J, Midthjell K, Krüger $\varnothing$, et al. The NordTrøndelag Health Study 1995-97 (HUNT 2): objectives, contents, methods and participation. Nor J Epidemiol 2003; 13: 19-32.

44 Mykletun A, Bjerkeset O, Dewey M, Prince M, Overland S, Stewart R. Anxiety, depression, and cause-specific mortality: the HUNT study. Psychosom Med 2007; 69: 323-331. 